\title{
Prognostic factors in resected pathological N1-stage II nonsmall cell lung cancer
}

\author{
Chao-Yu Liu*,\#,+, Jung-Jyh Hung*,\#,+, Bing-Yen Wang ", \\ Wen-Hu Hsu*, ${ }^{\star}$ and Yu-Chung Wu*,
}

ABSTRACT: Stage II nonsmall cell lung cancer (NSCLC) has been redefined in the seventh edition of tumour, node, metastasis (TNM) classification for lung cancer. Stages lla and Ilb both contain node-negative (NO) and node-positive (N1) subgroups. The aim of this study was to evaluate the prognostic factors for overall survival in patients with resected N1-stage II NSCLC.

Between January 1992 and December 2010, we retrospectively reviewed the clinicopathological characteristics of $163 \mathrm{~N} 1$-stage II (T1a-T2bN1M0) NSCLC in patients undergoing curative resection as primary treatment.

Median follow-up time was $\mathbf{3 7 . 2}$ months. The 1-, 3- and 5-yr overall survival rates were $\mathbf{8 5 . 3} \%$, $62.1 \%$ and $43.5 \%$, respectively. Tumour involvement of the hilar/interlobar nodal zone and poorly differentiated histological grade were significant predictors for worse overall survival using multivariate analysis $(p=0.001$ and $p=0.015$, respectively). There were trends toward worse overall survival in older patients and those with larger tumour size $(p=0.063$ and $p=0.075$, respectively).

In resected N1-stage II NSCLC, hilar/interlobar nodal involvement and poorly differentiated histological grade were significant predictors of worse overall survival. The differences in survival between these subgroups of patients may lead to the use of different adjuvant therapies or postsurgical follow-up strategies.

KEYWORDS: Hilar/interlobar nodal zone, histological grade, lymph nodes, stage II lung cancer

ung cancer is the leading cause of cancerrelated death worldwide. In Taiwan, it is also the most common cause of cancerrelated death in females and the second most common cause of death in males [1]. Surgical resection is the treatment of choice for early-stage nonsmall cell lung cancer (NSCLC). Even with curative surgical resection the 5-yr overall survival rate is between $52 \%$ and $61 \%$ for stage IIa, and between $43 \%$ and $47 \%$ for stage IIb [2-4].

The prognostic factors in lung cancer have been widely investigated in order to properly identify high risk patients and provide for their effective treatment. The seventh edition of the tumour, node, metastasis (TNM) classification [5, 6], published in 2009, reclassified malignant pleural effusions and separate tumour nodules. Other changes included new size cut-off points and new subdivisions of the $\mathrm{T} 1$ (into T1a and T1b), T2 (into T2a and T2b), and M1 (into M1a and M1b) descriptors. However, the nodal descriptor remained unchanged.

Node-positive (N1) disease represents a heterogeneous group of NSCLC with varying survival rates [7]. In recent decades, many authors have suggested that within the subset of patients with pathological N1 disease, the prognosis may differ according to the number, level or type of lymph nodes involved [8-14]. Stage II NSCLC included a relatively smaller number of patients compared with those with stage I NSCLC. In the present study, we evaluated the prognostic factors in N1stage II NSCLC with particular emphasis on the prognostic significance of the subgroups of N1 lymphadenopathy.

\section{PATIENTS AND METHODS}

\section{Patient selection}

The Institutional Review Board of Taipei Veterans General Hospital (Taipei, Taiwan) approved this study and granted a waiver of the informed consent process. From January 1992 to December 2010, a total of 210 consecutive patients who underwent pulmonary resection for pathologic N1-stage II NSCLC (T1a-2bN1M0) with curative intent at Taipei Veterans General Hospital were retrospectively reviewed. Adequate lymph node sampling ensures the accuracy of nodal status. LUDWIG et al. [15] suggested the number of lymph nodes sampled is somewhere between 11 and 16

\section{AFFILIATIONS}

*Division of Thoracic Surgery, Dept of Surgery, Taipei Veterans General Hospital,

${ }^{\text {\#} S c h o o l ~ o f ~ M e d i c i n e, ~ N a t i o n a l ~ Y a n g-~}$ Ming University, Taipei, and "Division of Thoracic Surgery, Dept of Surgery, Changhua Christian Hospital, and Chung Shan Medical University, Taichung, Taiwan.

+These authors contributed equally to this article.

CORRESPONDENCE

Y-C. Wu

Division of Thoracic Surgery

Dept of Surgery

Taipei Veterans General Hospital

No. 201

Sec. 2

Shih-Pai Road

Taipei 112

Taiwan

E-mail:wuyc@vghtpe.gov.tw

Received:

April 082012

Accepted after revision:

June 022012

First published online:

July 262012 
to evaluate nodal status in lung cancer surgery. Therefore, we restricted our analysis to patients who underwent sampling of $\geqslant 12$ regional lymph nodes during surgery to ensure the quality of nodal status evaluation. Patients with surgical mortality $(n=6,2.9 \%)$, defined as in-hospital death within 30 days after surgery, were excluded from our study. A total of 163 patients were included for analysis.

\section{Pre-operative work-up}

The pre-operative work-up included physical examination, serum biochemistry tests, flexible bronchoscopy, chest and upper abdominal computed tomography (CT), radionuclide bone scan, and CT or magnetic resonance imaging of the brain. In addition, positron emission tomography (PET)-CT scans were performed after 2007, if pre-operative tissue diagnosis was available. Mediastinoscopy was not routinely performed in pre-operative staging unless enlarged lymph nodes (with diameter $>1.0 \mathrm{~cm}$ ) were observed on CT and located on the contralateral side of the mediastinum from the cancer, or if the mediastinal lymph node uptake on fluorodeoxyglucose PET was $>2.5$ times the standard uptake values. Patients with suspected distant metastases were excluded from consideration for surgery. Once staged, a complete resection of all lung disease and lymph node sampling or radical dissection would be performed in all patients.

\section{Lymph node evaluation}

$\mathrm{N} 1$ and N2 lymph nodes were defined according to the lymph node map published by the International Association for the Study of Lung Cancer (IASLC) in 2009 [16]. An N1 node was classified into "hilar/interlobar" and "peripheral" zones, according to the anatomical location. Hilar nodes (station 10) included nodes immediately adjacent to the mainstem bronchus and hilar vessels including the proximal portions of the pulmonary veins and main pulmonary artery. Interlobar node (stations 11) included nodes between the origins of the lobar bronchi.

The lymph node dissection or sampling was performed routinely, including nodes stations $2 \mathrm{R}, 4 \mathrm{R}, 7 \mathrm{R}$ and $10 \mathrm{R}$ on the right side and 5L, 6L, 7L and 10L on the left side. In lobectomy, station 11 (interlobar lymph nodes) were routinely sampled. The lymph nodes sampled by surgeons were labelled accordingly for pathological examination. However, stations 12, 13 and 14 were mainly examined by pathologists. The pathologists dissected the resected lung tissue along the major bronchus into lung parenchyma. If lymph nodes were found along the bronchial trees, they were labelled according to their anatomical location. The whole lung tissue was later sliced at 1-cm intervals. If lymph nodes were found, they were named as an "intrapulmonary lymph node".

The total number of lymph nodes removed during surgery was defined as the number of lymph nodes dissected or sampled by the surgeon during surgery (including those sent for frozen diagnosis) and intrapulmonary lymph nodes examined by pathologists; all lymph nodes were examined by pathologists. The nodes harvested from mediastinoscopy were also included in this study. Pathological staging was assessed after examination of the resected specimens and all resected lymph nodes were examined for metastatic carcinoma. Disease stages were based on the seventh edition TNM classification of NSCLC [17].
None of our patients had prior neo-adjuvant radiotherapy or chemotherapy. Adjuvant chemotherapy was given to patients after surgical resection unless the patient was unable to tolerate it. All patients were followed-up on a three-monthly basis at our outpatient department during the initial 2 yrs after resection and semi-annually thereafter. The outcome was defined as death attributable to either cancer or noncancer causes. The length of survival was defined as the interval in months between the date of surgical resection and the date of either death or the last follow-up.

\section{Statistical analysis}

The overall survival rate was calculated by the Kaplan-Meier method. Univariate and multivariate analyses were performed by means of Cox proportional hazards model using the SPSS software (version 16.0; SPSS Inc., Chicago, IL, USA). A stepwise regression procedure was used. Clinicopathological factors such as age, sex, tumour size, histological type (squamous cell or other histological types), histological grading (well-to-moderately differentiated versus poorly differentiated), presence of visceral pleural invasion (VPI), involved lymph node number (solitary versus multiple), involved lymph node ratio (defined as the number of positive lymph nodes divided by the number of total resected lymph nodes) and level of lymph node involved (hilar/interlobar zone versus peripheral zone) were included in the univariate analyses. Variables with a p-value $<0.10$ in univariate analysis were entered into multivariate analysis. A pvalue $<0.05$ was considered statistically significant.

\section{RESULTS}

The median follow-up time for the 163 patients with surgically resected N1-stage II NSCLC was 37.2 months (mean 50.4 months, range 1.2-186.0 months). At the last follow-up session, $61(37.4 \%)$ patients were alive and $102(62.6 \%)$ patients died of either cancer or noncancer causes. The 1-, 3- and 5-yr overall survival rates were $85.3 \%, 62.1 \%$ and $43.5 \%$, respectively (fig. 1). The demographic and clinicopathological characteristics of these patients are summarised in table 1.

The mean age of our cohort was 65 yrs and the male-to-female ratio was 2.40. A total of $85(52.1 \%)$ patients had tumour within the right lung and $78(47.9 \%)$ patients had tumour within the left lung. Surgical resection was mainly lobectomy (131 (80.4\%) patients) for tumour removal, and only one patient had sublobar resection. The greatest dimension of each tumour was measured and recorded. $77(47.2 \%)$ patients had a tumour size $\leqslant 3 \mathrm{~cm}$ and $86(52.8 \%)$ patients had a tumour size $>3 \mathrm{~cm}$.

Adenocarcinoma was the main histological type within our cohort (90 (55.2\%) patients). According to the pathology report, histological grading was divided into well-, moderately and poorly differentiated carcinoma. However, there were 45 $(27.6 \%)$ patients with missing or histological grade "not described" in our cohort. Tumour with visceral pleural invasion was seen in 67 (41.1\%) patients. However, there were $14(8.6 \%)$ patients with "unknown status" regarding visceral pleural invasion. In the surgically dissected lymph nodes, a solitary metastatic lymph node was found in 88 (54.0\%) patients. 75 $(46.0 \%)$ patients were found to have $\geqslant 2$ lymph nodes metastases. Lymph node ratio was defined as the ratio of involved lymph nodes to the total number of removed nodes. 
A cut-off point of 0.06 was obtained to equally separate our cohort into two groups for comparison. According to IASLC lymph node map, which categorised lymph nodes into "zones", cancer involvement of hilar/interlobar zone was seen in $61(37.4 \%)$ patients and involvement of the peripheral zone was noted in $86(52.8 \%)$ patients. $16(9.8 \%)$ patients had both zones involved.

The factors associated with lung cancer prognosis were evaluated using univariate analysis. This analysis showed that age (as a continuous variable, $\mathrm{p}=0.001$ ), cancer-involved lymph node ratio $(\mathrm{p}=0.044)$ and cancer involvement of hilar/ interlobar lymph nodes $(p=0.013)$ had a significant influence on overall survival (table 2). Survival was significantly better in younger patients, patients with lower cancer-involved lymph node ratios $(\leqslant 0.06)$ and patients who had metastatic N1 lymph node involvement of other regions besides the hilar/interlobar zone. The hazard of death was greater in patients with a tumour size $>3 \mathrm{~cm}$ (hazard ratio (HR) 1.440, 95\% confidence interval (CI) $0.970-2.138 ; \mathrm{p}=0.070)$, poorlydifferentiated cell type (HR 1.589, 95\% CI 0.968-2.609; $\mathrm{p}=0.067)$, and multiple cancer-involved N1 lymph nodes (HR 1.325, 95\% CI 0.896-1.961; $\mathrm{p}=0.159$ ). Although these factors did not reach statistical significance, the trend to predict survival was comparable with other reports from the literature. The variables with a p-value $<0.10$ were entered into multivariate analysis. Only histological grade $(p=0.015)$ and tumour involvement of hilar/interlobar lymph nodes $(p=0.001)$ were significant prognostic indicators on multivariate analysis (table 3). Older patients $(p=0.063)$, large tumour size $(\mathrm{p}=0.075)$ and high involved lymph node ratio $(\mathrm{p}=0.199)$ showed a trend toward poorer overall survival.

\section{DISCUSSION}

Staging is important for predicting patient prognosis and selecting appropriate lung cancer treatment. The IASLC established an international staging committee to formulate a revision of the TNM classification of lung cancer that was published in the seventh edition of the Union International

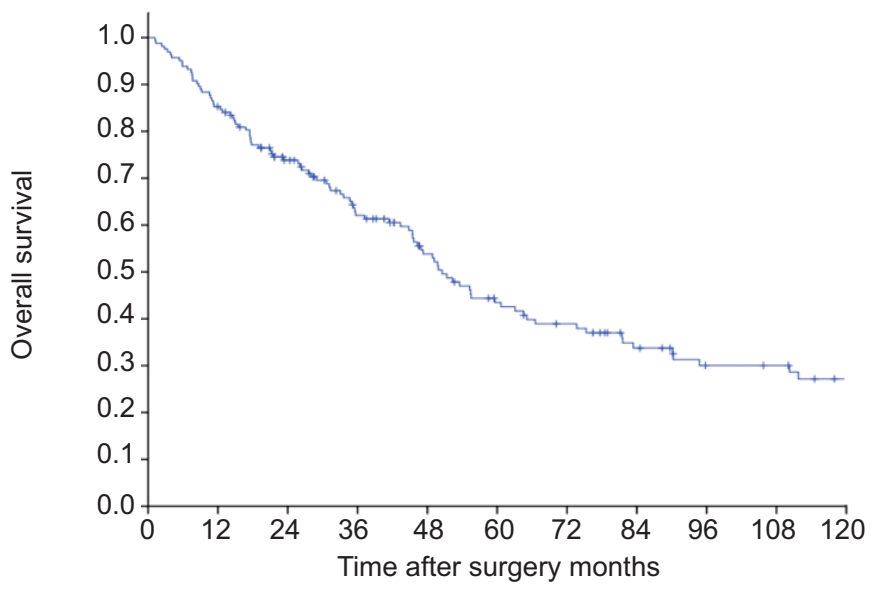

Patients at risk $n$

$\begin{array}{lllllllllll}163 & 138 & 107 & 82 & 63 & 48 & 41 & 31 & 23 & 22 & 17\end{array}$

FIGURE 1. The Kaplan-Meier survival curve of $163 \mathrm{~N} 1$-stage II nonsmall cell lung cancer patients after curative surgical resection.
Contre le Cancer and American Joint Commission on Cancer (AJCC) cancer staging manuals in $2009[5,6]$. The seventh edition of TNM classification of lung cancer provided a revision of the $\mathrm{T}$ descriptor, which divided $\mathrm{T} 1$ into $\mathrm{T} 1 \mathrm{a}$ and $\mathrm{T} 1 \mathrm{~b}$, and $\mathrm{T} 2$ into $\mathrm{T} 2 \mathrm{a}$ and $\mathrm{T} 2 \mathrm{~b}$ according to new tumour size cut-off points [17]. Although the $\mathrm{N}$ descriptors remained unchanged in the new edition of TNM system, the IASLC staging committee developed a revised lymph node map that grouped lymph node stations into "zones", i.e. peripheral or hilar for N1, and upper or lower mediastinal, or aortopulmonary or subcarinal for $\mathrm{N} 2$ nodes [16].

The first lymph node map, developed by NARUKE [18] during the 1960s, was initially widely used in North America, Europe

\begin{tabular}{|c|c|c|}
\hline TABLE 1 & \multicolumn{2}{|c|}{$\begin{array}{l}\text { Characteristics of } 163 \text { patients of resected N1- } \\
\text { stage II nonsmall cell lung cancer }\end{array}$} \\
\hline Age yrs & & $67(65.2 \pm 10.1)$ \\
\hline \multicolumn{3}{|l|}{ Sex } \\
\hline Male & & $115(70.6)$ \\
\hline Female & & $48(29.4)$ \\
\hline \multicolumn{3}{|c|}{ Tumour location } \\
\hline Right lung & & $85(52.1)$ \\
\hline Left lung & & $78(47.9)$ \\
\hline \multicolumn{3}{|c|}{ Tumour size $\mathrm{cm}$} \\
\hline$\leqslant 2$ & & $33(20.2)$ \\
\hline$>2$ to $\leqslant 3$ & & $44(27.0)$ \\
\hline$>3$ to $\leqslant 5$ & & 65 (39.9) \\
\hline$>5$ to $\leqslant 7$ & & $21(12.9)$ \\
\hline \multicolumn{3}{|c|}{ Pathological stage } \\
\hline Ila & & $142(87.1)$ \\
\hline $11 \mathrm{~b}$ & & $21(12.9)$ \\
\hline \multicolumn{3}{|c|}{ Extent of pulmonary resection } \\
\hline Lobectomy & r wedge resection & $132(81.6)$ \\
\hline Bilobectomy & or pneumonectomy & $31(18.4)$ \\
\hline \multicolumn{3}{|c|}{ Histological type } \\
\hline Squamous & ell carcinoma & $57(35.0)$ \\
\hline Adenocarcir & oma & $90(55.2)$ \\
\hline Others & & $16(9.8)$ \\
\hline \multicolumn{3}{|c|}{ Histological grade } \\
\hline Well-to-mod & rately differentiated & $81(49.7)$ \\
\hline Poorly differ & entiated & $37(22.7)$ \\
\hline Unknown & & $45(27.6)$ \\
\hline \multicolumn{3}{|c|}{ Visceral pleural invasion } \\
\hline Present & & $67(41.1)$ \\
\hline Absent & & $82(50.3)$ \\
\hline Unknown & & $14(8.6)$ \\
\hline \multicolumn{3}{|c|}{ Lymph nodes involved $n$} \\
\hline Solitary & & $88(54.0)$ \\
\hline Multiple & & $75(46.0)$ \\
\hline \multicolumn{3}{|c|}{ Involved lymph node ratio } \\
\hline$\leqslant 0.06$ & & $84(51.5)$ \\
\hline$>0.06$ & & $79(48.5)$ \\
\hline \multicolumn{3}{|c|}{ Zone of lymph node involved } \\
\hline Hilar/interlok & & $61(37.4)$ \\
\hline Peripheral & & $86(52.8)$ \\
\hline Both & & $16(9.8)$ \\
\hline
\end{tabular}

Data are presented as median (mean $\pm \mathrm{SD})$ or $\mathrm{n}(\%)$. 


\begin{tabular}{|c|c|c|c|}
\hline \multirow{2}{*}{$\begin{array}{l}\text { TABLE } 2 \\
\text { Variables }\end{array}$} & \multicolumn{3}{|c|}{$\begin{array}{l}\text { Univariate analyses for overall survival in patients } \\
\text { with resected N1-stage II nonsmall cell lung } \\
\text { cancer }\end{array}$} \\
\hline & & HR $(95 \%$ Cl) & $\mathrm{p}$-value \\
\hline \multicolumn{2}{|l|}{ Age yrs } & $1.036(1.014-1.060)$ & 0.001 \\
\hline \multicolumn{2}{|l|}{ Sex } & & 0.857 \\
\hline \multicolumn{2}{|l|}{ Female } & 1 & \\
\hline \multicolumn{2}{|l|}{ Male } & $1.041(0.673-1.611)$ & \\
\hline \multicolumn{2}{|c|}{ Tumour size } & & 0.070 \\
\hline \multicolumn{2}{|c|}{$\leqslant 3 \mathrm{~cm}$} & 1 & \\
\hline \multicolumn{2}{|c|}{$>3 \mathrm{~cm}(\leqslant 7 \mathrm{~cm})$} & $1.440(0.970-2.138)$ & \\
\hline \multicolumn{2}{|c|}{ Pathological stage } & & 0.249 \\
\hline \multicolumn{2}{|l|}{ Ila } & 1 & \\
\hline \multicolumn{2}{|l|}{$\| l b$} & $1.382(0.797-2.394)$ & \\
\hline \multicolumn{2}{|c|}{ Histology type } & & 0.686 \\
\hline \multicolumn{2}{|c|}{ Squamous cell } & 1 & \\
\hline \multicolumn{2}{|c|}{ Nonsquamous cell } & $1.089(0.721-1.645)$ & \\
\hline \multicolumn{2}{|c|}{ Histological grade } & & 0.067 \\
\hline \multicolumn{2}{|c|}{$\begin{array}{l}\text { Well-to-moderately } \\
\text { differentiated }\end{array}$} & 1 & \\
\hline \multicolumn{2}{|c|}{ Poorly differentiated } & 1.589 ( 0.968-2.609) & \\
\hline \multicolumn{2}{|c|}{ Visceral pleural invasion } & & 0.315 \\
\hline \multicolumn{2}{|l|}{ No } & 1 & \\
\hline \multicolumn{2}{|l|}{ Yes } & $1.251(0.808-1.937)$ & \\
\hline \multicolumn{2}{|c|}{ Lymph nodes involved $n$} & & 0.159 \\
\hline \multicolumn{2}{|l|}{ Solitary } & 1 & \\
\hline \multicolumn{2}{|l|}{ Multiple } & 1.325 & \\
\hline \multicolumn{2}{|c|}{ Involved lymph node ratio } & & 0.044 \\
\hline \multicolumn{2}{|l|}{$\leqslant 0.06$} & 1 & \\
\hline \multicolumn{2}{|l|}{$>0.06$} & $1.499(1.010-2.224)$ & \\
\hline \multicolumn{2}{|c|}{$\begin{array}{l}\text { Hilar/interlobar lymph node } \\
\text { involved }\end{array}$} & & 0.013 \\
\hline \multicolumn{2}{|l|}{ No } & 1 & \\
\hline \multicolumn{2}{|l|}{ Yes } & $1.651(1.112-2.452)$ & \\
\hline
\end{tabular}

HR: hazard ratio.

and Japan. However, subsequent attempts to refine the anatomical descriptors of the Naruke map led to the development of maps by the American Thoracic Society (ATS) and the so-called Mountain-Dresler modification of the ATS map (MDATS). The revised lymph node map reconciled differences between the Japanese (Naruke) and MD-ATS maps and provided more specific anatomical definitions for each of the lymph node stations [16]. In the new version of TNM classification system, stage IIa and stage IIb both contain node-positive (stage IIa contains T1a-T2aN1 and stage IIb contains $\mathrm{T} 2 \mathrm{bN} 1$ ) and node-negative (stage Ila contains T2bN0 and stage IIb contains T3N0) cases. In the present study, given the revised lymph node map and a new staging system, we examined the prognostic factors used to predict survival in the node-positive stage II NSCLC, with emphasis on the characteristics of N1 lymphadenopathy.

The status of regional lymph nodes is a strong prognostic indicator and has a major impact on treatment decisions for patients with NSCLC [19]. Although the N descriptors in the

\begin{tabular}{|c|c|c|c|}
\hline \multirow{2}{*}{ TABLE } & \multicolumn{3}{|c|}{$\begin{array}{l}\text { Multivariate analyses for overall survival in } \\
\text { patients with resected N1-stage II nonsmall cell } \\
\text { lung cancer }\end{array}$} \\
\hline & & HR $(95 \% \mathrm{Cl})$ & $\mathrm{p}$-value \\
\hline \multicolumn{2}{|l|}{ Age yrs } & $1.028(0.998-1.058)$ & 0.063 \\
\hline \multicolumn{2}{|c|}{ Tumour size } & & 0.075 \\
\hline \multicolumn{2}{|l|}{$\leqslant 3 \mathrm{~cm}$} & 1 & \\
\hline \multicolumn{2}{|c|}{$>3 \mathrm{~cm}(\leqslant 7 \mathrm{~cm})$} & $1.631(0.953-2.793)$ & \\
\hline \multicolumn{2}{|c|}{ Histological grade } & & 0.015 \\
\hline \multicolumn{2}{|c|}{$\begin{array}{l}\text { Well-to-moderately } \\
\text { differentiated }\end{array}$} & 1 & \\
\hline \multicolumn{2}{|c|}{ Poorly differentiated } & $1.975(1.142-3.414)$ & \\
\hline \multicolumn{2}{|c|}{ Involved lymph node ratio } & & 0.199 \\
\hline \multicolumn{2}{|l|}{$\leqslant 0.06$} & 1 & \\
\hline \multicolumn{2}{|l|}{$>0.06$} & $1.404(0.857-2.355)$ & \\
\hline \multicolumn{2}{|c|}{$\begin{array}{l}\text { Hilar/interlobar lymph node } \\
\text { involved }\end{array}$} & & 0.001 \\
\hline No & & 1 & \\
\hline Yes & & $2.595(1.507-4.469)$ & \\
\hline
\end{tabular}

HR: hazard ratio

new edition of TNM system were not changed, several studies have reported that, within the N1 category, there are several prognostic modifiers. These include the number of lymph nodes involved (solitary versus multiple) [19-21], the ratio of lymph nodes involved [20, 21], the level of lymph nodes involved (hilar versus lobar) [7, 11, 12, 22, 23], and the pattern of lymph nodes involved (direct invasion versus separate metastases) [24, 25]. Several studies have highlighted that N1 disease represents a heterogeneous group of patients with different lymph node-related factors affecting prognosis. The identification of subgroups of patients with different outcomes could help to tailor post-operative management, such as aggressive chemotherapy or closer follow-up strategy.

The number of involved lymph nodes has been recognised as a significant predictor of survival in N1 NSCLC. JONNALAGADDA et al. [21] analysed the data from the Surveillance, Epidemiology, and End Results database, including 3,399 patients with N1 NSCLC. They concluded that the number of positive lymph nodes is an independent prognostic factor for survival in patients with N1 NSCLC. In our study, with a relatively smaller sample size, multiple lymph node involvement with tumour showed a trend toward poorer overall survival on univariate analysis (HR 1.325, 95\% CI 0.896-1.961; $\mathrm{p}=0.159$ ). However, the association between survival and number of tumour-involved lymph nodes is inherently confounded by the number of removed lymph nodes. Therefore, WISNIVESKY et al. [26] reported the prognostic impact of the lymph node ratio (LNR) on 1,682 patients aged $>65$ yrs diagnosed with pathological N1 NSCLC [26]. A median value of eight lymph nodes was resected in each patient within their cohort. They divided their patients into three groups according to the LNR: $\leqslant 0.15,0.15-0.5$ and $>0.5$. Within the population studied, they found that the overall survival was significantly worse as the LNR increased. In our 
series, a median number of 23 lymph nodes was resected, which was three times larger than the median number resected in the study by WISNIVESKY et al. [26]. We also found that patients with a LNR $>0.06$ had a significantly higher hazard risk of death (HR $1.499,95 \%$ CI 1.010-2.224) than patients with a LNR $\leqslant 0.06$ on univariate analysis $(\mathrm{p}=0.044)$. Our study echoed other previous studies in which LNR was found to be a prognostic factor for survival in patients with N1 NSCLC.

In addition to the number and ratio of lymph node involvement, the level of nodal involvement is a frequently investigated prognostic factor in N1 NSCLC, with a worse outcome for hilar station involvement compared with interlobar or more peripheral station metastases. SHIMADA et al. [22], with the use of the lymph node map developed by NARUKE et al. [27], concluded that patients with node 10 (hilar)-positive N1 disease have an unfavourable prognosis, as the disease behaves like N2 disease [22]. With the use of the IASLC lymph node map, we showed that patients with tumour involvement of the hilar/interlobar zone had a significantly higher hazard risk of death both on univariate analysis (HR 1.651, 95\% CI 1.112-2.452; $\mathrm{p}=0.013$ ) and multivariate analysis (HR 2.595, 95\% CI 1.490-4.427; p=0.001). The 5-yr overall survival rates in patients with and without tumour involvement of hilar/interlobar nodal zone were $37.1 \%$ and $49.9 \%$, respectively $(p=0.012)$ (fig. 2$)$. Our study showed that the tumour involvement of hilar/interlobar zone is an independent prognostic factor in N1-stage II NSCLC.

We also found that histological grade (cell differentiation) was a significant predictor for overall survival in N1-stage II NSCLC. Patients with poorly differentiated carcinoma had an increased hazard risk of death both on univariate analysis (HR 1.589; 95\% CI 0.968-2.609; $\mathrm{p}=0.067$ ) and multivariate analysis (HR 1.997; 95\% CI 1.154-3.455; $\mathrm{p}=0.013$ ). In the published literature, the impact of cell differentiation on survival was

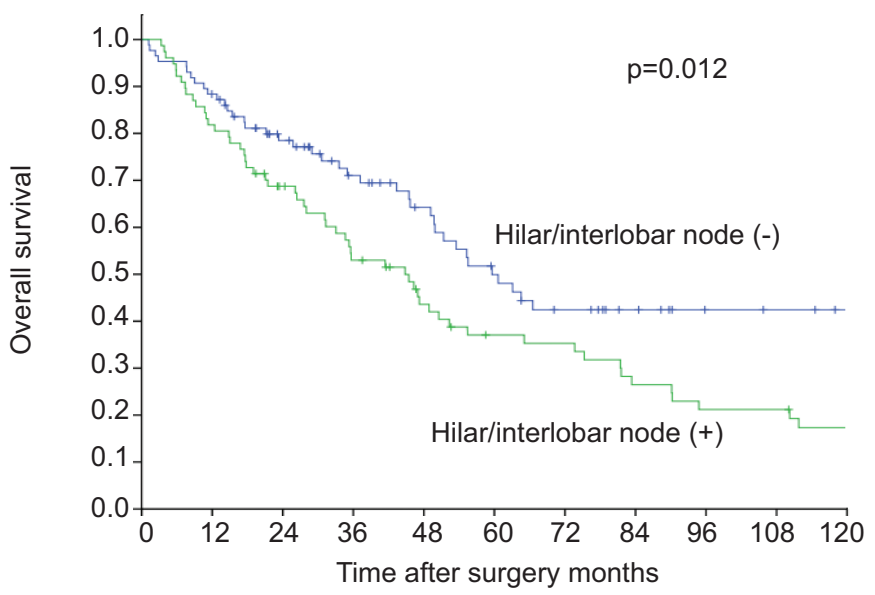

Patients at risk $\mathrm{n}$

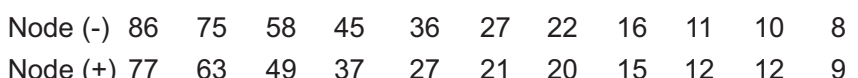

FIGURE 2. The Kaplan-Meier survival curves of $163 \mathrm{~N} 1$-stage II nonsmall cell lung cancer patients who had hilar/interlobar node positive and negative. Log rank $p<0.001$ discussed primarily in patients with stage I NSCLC. Hsu et al. [28] reported that in NSCLC patients with stage Ib (pT2NOM0), cell differentiation is a significant prognosticator for overall survival $(p=0.0024)$. In a previous study, we also showed that cell differentiation was associated with overall survival in stage I NSCLC $(p=0.04)$ [29]. However, cell differentiation has rarely been discussed in stage II NSCLC. We noted that patients with poorly differentiated carcinoma were associated with poorer overall survival after including other prognostic factors for mutual adjustment $(p=0.015)$. However, larger sample sizes are needed to confirm this finding.

The influence of visceral pleural invasion (VPI) on stage II NSCLC remains unclear. VAN VELZEN et al. [11] reported that the presence of VPI unfavourably affected survival in T2N1M0 NSCLC patients $(p=0.0093)$. However, in the study by RIQUET et al. [12], VPI did not correlate with overall survival in pathological N1 NSCLC patients $(\mathrm{p}=0.65)$. In our study, patients with VPI showed a trend toward a slightly higher hazard risk of death compared with their counterparts on univariate analysis; however, the result was not significant (HR 1.251, 95\% CI 0.808-1.937; $\mathrm{p}=0.315)$.

Lymph node metastases are present in most cases of stage II NSCLC. However, the impact of any non-nodal factor is less clear than in stage I disease. HoLmEs [30] reported significant survival differences favouring squamous cell lung cancer in T1N1 and ICHINOSE et al. [31] showed similar results in T1-2N1 disease. However, neither MARTINI et al. [32] nor YANO et al. [8] found any significant histological benefit favouring squamous cell lung cancer over nonsquamous cell lung cancer. CHANSKY et al. [33] published a prognostic analysis of a cohort of 9,137 surgically managed stage I to stage IIIA NSCLC patients (the IASLC staging project). In their study, the squamous cell carcinoma may have a better prognosis than the nonbronchioloalveolar carcinoma type adenocarcinoma, particularly among male patients with early-stage disease. Our results from a population of T1a-2bN1 NSCLC showed no survival benefit in squamous cell carcinoma over nonsquamous cell carcinoma. In an adjusted analysis for sex, the survival prognosis remained similar in both groups. Therefore, our study failed to identify the cancer cell type to be a significant prognostic factor in surgically managed N1-stage II NSCLC patients. The results of CHANSKY et al. [33] and our study may reflect the fact that the prognostic impact of cell type, compared with nodal status, are less significant in N1 NSCLC.

Tumour size in stage II NSCLC does not appear to significantly affect overall survival. MARTINI et al. [32] found that tumour size $<3 \mathrm{~cm}$ in diameter had a higher survival rate compared with those $>5 \mathrm{~cm}$. In our series of N1-stage II NSCLC, tumour size $>3 \mathrm{~cm}$ but $\leqslant 7 \mathrm{~cm}$ had an increased hazard risk of death compared with those $\leqslant 3 \mathrm{~cm}$ in diameter (HR 1.631; $\mathrm{p}=0.075$ ). Although our result did not reach statistical significance, it implied that the tumour size may have an impact on survival in N1-stage II NSCLC if a larger-sized population is studied.

Our study had several limitations. We performed a retrospective analysis over a long period of time. Data are lacking in some patients for certain variables, such as visceral pleural 
invasion and histological grade, which may have affected our results. Several different surgeons performed the pulmonary resections and not all patients received radical mediastinal lymph node dissection in our cohort. Additionally, resected N1 nodes were not examined and reported by the same group of pathologists. Therefore, the quantity and quality of lymph node dissection/sampling were not the same among all our patients, despite the cases we excluded from our study with $<12$ sampled lymph nodes. Lack of data regarding recurrencefree survival was another limitation of our study.

\section{Conclusions}

Stage II NSCLC comprises a heterogeneous group of nodepositive and -negative tumours. Prognostic factor analysis confers a better evaluation of this subgroup of patient. In the present study of N1-stage II NSCLC, hilar/interlobar nodal involvement and poorly differentiated histological grade were significant predictors of worse overall survival. The differences in survival between these subgroups of patients may lead to the use of different adjuvant therapies or post-surgical followup strategies. Future clinical trials will have to consider the survival difference of these subgroups of patient and stratification will be necessary to test adjuvant therapies.

\section{SUPPORT STATEMENT}

This work was supported in part by Taiwan National Science Council (NSC 100-2314-B-075-004-MY2) (Y-C. Wu), Center of Excellence for Cancer Research at Taipei Veterans General Hospital (DOH101-TD-C111-007) (Y-C. Wu), KS Lu Lung Cancer Foundation (Y-C. Wu and J.J. Hung), National Science Council (NSC-101-2314-B-075-010) (J.J. Hung), and Taipei Veterans General Hospital (V102B-021) (J.J. Hung).

\section{STATEMENT OF INTEREST}

None declared.

\section{REFERENCE}

1 Cancer Registry Annual Report, Taiwan 2008. Republic of China, Taipei, Bureau of Health Promotion, Department of Health.

2 Asamura H, Goya T, Koshiishi Y, et al. A Japanese Lung Cancer Registry Study: prognosis of 13010 resected lung cancer. J Thorac Oncol 2008; 3: 46-52.

3 Naruke T, Tsuchiya R, Kondo H, et al. Prognosis and survival after resection for bronchogenic carcinoma based on the 1997 TNMstaging classification: the Japanese experience. Ann Thorac Surg 2001; 71: 1759-1764.

4 van Rens MTM, de la Rivière AB, Elbers HR, et al. Prognostic assessment of 2,361 patients who underwent pulmonary resection for non-small cell lung cancer stage I, II, and IIIA. Chest 2000; 117: 374-379.

5 American Joint Committee on Cancer. AJCC Cancer Staging Manual, 7th Edn. New York, Springer, 2010.

6 International Union Against Cancer. TNM Classification of Malignant Tumours, 7th Edn. Oxford, UK, Wiley-Blackwell, 2009.

7 Caldarella A, Crocetti E, Comin CE, et al. Prognostic variability among nonsmall cell lung cancer patients with pathologic N1 lymph node involvement. Epidemiological figures with strong clinical implications. Cancer 2006; 107: 793-798.

8 Yano $\mathrm{T}$, Yokoyama $\mathrm{H}$, Inoue $\mathrm{T}$, et al. Surgical results and prognostic factors of pathologic N1 disease in non-small cell carcinoma of the lung. Significance of N1 level: lobar or hilar nodes. J Thorac Cardiovasc Surg 1994; 107: 1398-1402.
9 Osaki T, Nagashimatsu T, Yoshimatsu T, et al. Survival and characteristics of lymph node involvement in patients with N1 non-small cell lung cancer. Lung Cancer 2004; 43: 151-157.

10 Demir A, Turna A, Kocaturk C, et al. Prognostic significance of surgical-pathologic N1 lymph node involvement in non-small cell lung cancer. Ann Thorac Surg 2009; 87: 1014-1022.

11 Van Velzen E, Snijder RJ, Brutel de la Rivière A, et al. Lymph node type as a prognostic factor for survival in T2 N1 M0 non-small cell lung carcinoma. Ann Thorac Surg 1997; 63: 1436-1440.

12 Riquet M, Manac'h D, Le Pimpec-Barthes F, et al. Prognostic significance of surgical-pathologic N1 disease in non-small cell carcinoma of the lung. Ann Thorac Surg 1999; 67: 1572-1576.

13 Fujimoto T, Cassivi SD, Yang P, et al. Completely resected N1 nonsmall cell lung cancer: factors affecting recurrence and long-term survival. J Thorac Cardiovasc Surg 2006; 132: 499-506.

14 Marra A, Hillejan L, Zaboura G, et al. Pathologic N1 non-small cell lung cancer: correlation between pattern of lymphatic spread and prognosis. J Thorac Cardiovasc Surg 2003; 125: 543-553.

15 Ludwig MS, Goodman M, Miller DL, et al. Postoperative survival and the number of lymph nodes sampled during resection of nodenegative non-small cell lung cancer. Chest 2005; 128: 1545-1550.

16 Rusch VW, Asamura H, Watanabe H, et al. The IASLC Lung Cancer Staging Project: a proposal for a new international lymph node map in the forthcoming seventh edn of the TNM classification for lung cancer. J Thorac Oncol 2009; 4: 568-577.

17 Rusch VW, Crowley J, Giroux DJ, et al. The IASLC Lung Cancer Staging Project: proposals for the revision of the $\mathrm{N}$ descriptors in the forthcoming seventh edn of the TNM classification for lung cancer. J Thorac Oncol 2007; 2: 603-612.

18 Naruke T. The spread of lung cancer and its relevance to surgery. Nippon Kyobu Geka Gakkai Zasshi 1967; 68: 1607-1621.

19 Lee JG, Lee CY, Park IK, et al. Number of metastatic lymph nodes in resected non-small cell lung cancer predicts patient survival. Ann Thorac Surg 2008; 85: 211-215.

20 Bria E, Milella M, Sperduti I, et al. A novel clinical prognostic score incorporating the number of resected lymph-nodes to predict recurrence and survival in non-small-cell lung cancer. Lung Cancer 2009; 66: 365-371.

21 Jonnalagadda S, Smith C, Mhango G, et al. The number of lymph node metastases as a prognostic factor in patients with N1 nonsmall cell lung cancer. Chest 2011; 140: 433-440.

22 Shimada $Y$, Tsuboi M, Saji $H$, et al. The prognostic impact of main bronchial lymph node involvement in non-small cell lung carcinoma: suggestions for a modification of the staging system. Ann Thorac Surg 2009; 88: 1583-1588.

23 Casali C, Stefani A, Morandi U. N1 non-small-cell lung cancer. A 20year surgical experience. Asian Cardiovasc Thorac Ann 2011; 19: 217-224.

24 Nakao M, Yoshida J, Ishii G, et al. Prognostic impact of node involvement pattern in $\mathrm{pN} 1$ non-small cell lung cancer patients. J Thorac Oncol 2010; 5: 1576-1582.

25 Nakao M, Yoshida J, Ishii G, et al. Prognostic impact of node involvement pattern in pulmonary pN1 squamous cell carcinoma patients. J Thorac Oncol 2010; 5: 504-509.

26 Wisnivesky JP, Arciniega J, Mhango G, et al. Lymph node ratio as a prognostic factor in elderly patients with pathological N1 nonsmall cell lung cancer. Thorax 2011; 66: 287-293.

27 Naruke T, Suemasu K, Ishikawa S. Lymph node mapping and curability at various levels of metastasis in resected lung cancer. J Thorac Cardiovasc Surg 1978; 76: 832-839.

28 Hsu CP, Hsia JY, Chang GC, et al. Surgical-pathologic factors affect long-term outcomes in stage IB (pT2 N0 M0) non-small cell lung cancer: a heterogeneous disease. J Thorac Cardiovasc Surg 2009; 138: 426-433.

$29 \mathrm{Wu}$ Y-C, Lin C-FJ, Hsu W-H, et al. Long-term results of pathological stage I non-small cell lung cancer: validation of using the number of totally removed lymph nodes as a staging control. Eur J Cardiothoracic Surg 2003; 24: 994-1001. 
30 Holmes EC. Treatment of stage II lung cancer (T1N1 and T2N1). Surg Clin North Am 1987; 67: 945.

31 Ichinose $\mathrm{Y}, \mathrm{Yano} \mathrm{T}$, Asoh $\mathrm{H}$, et al. Prognostic factors obtained by a pathologic examination in completely resected non-small-cell lung cancer. An analysis in each pathologic stage. J Thorac Cardiovasc Surg 1995; 110: 601-605.
32 Martini N, Burt ME, Bains MS, et al. Survival after resection of stage II non-small cell lung cancer. Ann Thorac Surg 1992; 54: 460-465.

33 Chansky K, Sculier J-P, Crowley JJ. The International Association for the Study of Lung Cancer Staging Project: prognostic factors and pathologic TNM stage in surgically managed non-small cell lung cancer. J Thorac Oncol 2009; 4: 792-801. 